\title{
Tracer Dating and Ocean Ventilation
}

\author{
G. Thiele' and J. L. Sarmiento
}

Atmospheric and Oceanic Sciences Program, Princeton University, Princeton, New Jersey

\begin{abstract}
The interpretation of transient tracer observations depends on difficult to obtain information on the evolution in time of the tracer boundary conditions and interior distributions. Recent studies have attempted to circumvent this problem by making use of a derived quantity, age, based on the simultaneous distribution of two complementary tracers, such as tritium and its daughter, helium 3 . The age is defined with reference to the surface such that the boundary condition takes on a constant value of zero. We use a two-dimensional model to explore the circumstances under which such a combination of conservation equations for two complementary tracers can lead to a cancellation of the time derivative terms. An interesting aspect of this approach is that mixing can serve as a source or sink of tracer based age. We define an idealized "ventilation age tracer" that is conservative with respect to mixing, and we explore how its behavior compares with that of the tracer-based ages over a range of advective and diffusive parameters.
\end{abstract}

\section{INTRODUCTION}

Transient tracers such as tritium and tritiugenic helium 3, chlorofluorocarbons (especially CFC-11 and CFC-12), and radiocarbon produced by nuclear bomb tests have entered the oceans primarily during the past 30 years. The inherent time scale of these tracers matches very well typical time scales for thermocline ventilation as well as other important oceanic processes such as deep water formation. They have been used with some success to study the time scales of thermocline ventilation [e.g., Sarmiento, 1983; Jenkins, 1987] and oxygen utilization rates (OUR) [e.g., Jenkins, $1977,1980,1982,1987$ ] as well as other processes such as equatorial upwelling rates [Broecker et al., 1978; Quay et al., 1983; Wunsch, 1984] and transport of upper North Atlantic Deep Water [Weiss et al., 1985]. The problem of coping with the nonsteady state aspect of these tracers has been dealt with in many ways, few of them truly satisfactory. For example, Rooth and Ostlund [1972] chose to estimate the diapycnic diffusivity in a region where there was some evidence that the tracer distributions were approximately in steady state at the time of their measurements. Wunsch [1984] used a similar steady state assumption in his study of equatorial upwelling using bomb radiocarbon. Such an argument cannot be applied in most regions of the ocean, however; indeed, one can question whether it applies even in the above situations. Therefore one generally would expect that it would be necessary to know something about the evolution of the tracer concentration in time, as well as the time history of the boundary conditions for that tracer over the same span of time. For example, Sarmiento's [1983] tritium box model of the thermocline solved the conservation equation for the period of time between 1952, before nuclear bomb tests had injected a significant amount of tritium into the oceans, and 1972 , when a single realization of the tracer field was obtained by a series of field studies. The surface concentration time history of Dreisigacker and Roether [1978] was used as a boundary condition. Such an

\footnotetext{
${ }^{1}$ Now at Deutsche Forschungs- und Versuchasanstalt für Luftund Raumfahrt, Cologne, Federal Republic of Germany.

Copyright 1990 by the American Geophysical Union.

Paper number 89JC01132.

0148-0227/90/89JC-01132\$05.00
}

approach requires an excellent knowledge of the boundary condition as well as the tracer distribution at more than one point of time, neither of which is generally available in satisfactory form. The impact of this problem for a particular case in the east Atlantic has been explored in considerable detail by Wunsch [1988].

It is because of this problem of resolving the temporal variability of the transient tracer distributions and their boundary conditions that we have been watching with great interest the development of ideas for using multiple transient tracers to date water parcels. Jenkins has done such work using tritium and its daughter, helium 3 [e.g., Jenkins and Clarke, 1976], as has Fuchs [1987]. Weiss et al. [1985] has done such work using the ratio of CFC-11 to CFC-12. A major advantage of this approach is that the surface boundary conditions change from concentrations which vary in a complex way with time, to a simple steady state condition of age $=0$. In addition, to the extent that such tracer-derived ages are in steady state for any region of the ocean, one can avoid the problem of having to know the evolution in time of the tracer fields by making use of tracer-derived ages instead [Roether, 1989]. Basically, two tracer conservation equations with large time derivatives are combined in such a way as to form a third equation with a very small time derivative.

The derivation of a tracer derived age equation leads us to define an idealized "age tracer" that provides a measure of ventilation time of the thermocline and deep ocean with respect to the surface (indeed, we will use this tracer to define what we mean by ventilation time). The only difference between this idealized ventilation age tracer and the tracer-derived age equations, in regions where the latter are in steady state, is that the tracer-derived age equations include mixing terms that do not conserve age. This difference does not constitute a problem in using the tracerderived age equation to obtain constraints on the flow and mixing fields. It is of concern, however, if one is actually trying to obtain the ventilation time, for example to find the average oxygen utilization rate of a water parcel over some time interval. Thus Jenkins [1977, 1980, 1982, 1987], in his various studies of OUR, and Weiss et al. [1985] in their study of North Atlantic Deep Water transport, have had to make some very restrictive assumptions about the effect of mixing in order to make use of the concept of age dating. For 
example, Jenkins has assumed, in effect, that the nonconservative mixing terms in the equation are negligible. In such a case, the ingrowth of helium 3 from tritium provides a time clock accurate, with present measurement precisions, to approximately 1 month for the time since a water parcel containing the tracers last departed the surface, where the helium 3 is set to a known value. Weiss et al., on the other hand, in their study of the western boundary current in the Atlantic Ocean, assumed that all mixing that occurred was with waters that were essentially free of chlorofluorocarbons, such that the ratio of these tracers was the same as when it left the surface. The ratio is a function of time up to 1975 and can be used under these assumptions to date the time since the chlorofluorocarbon left the surface. The extent of dilution of the tracer is a function of the amount of mixing, which can therefore be readily deduced as well.

The major goal of the study presented in this paper was to gain a better understanding of how to interpret transient tracer ages. The definition of an idealized "ventilation age tracer" provides a convenient reference point and focuses our attention on the one aspect of the tracer-based ages that differs from the idealized tracer, that is to say, their nonconservative behavior with respect to mixing. A major reason for our interest in the sensitivity to mixing is that we have previously argued that important discrepancies in various tracer estimates of oxygen utilization and thermocline ventilation rates may be due in part to the fact that in the presence of mixing, different tracers will often give different ages for the same water parcel [Sarmiento et al., 1990]. In addition, we are interested in understanding the extent to which sensitivity to mixing might be useful in providing constraints on the magnitude of mixing. We choose as a vehicle for our study a two-dimensional model intended to represent an isopycnal surface in the upper main thermocline.

\section{Tracer Equations}

A derivation of the tritium- ${ }^{3} \mathrm{He}$ age equation was first given by Jenkins [1987]. We derive here a slightly different version. Suppose we have two tracers, $\theta$ and $\mu$, which obey the following equations:

$$
\begin{gathered}
\theta_{t}=K \nabla^{2} \theta-u \nabla \theta \\
\mu_{t}=K \nabla^{2} \mu-u \nabla \mu-\lambda \mu
\end{gathered}
$$

Subscripts denote partial derivatives. Suppose further that an age can be defined from the tracers $\theta$ and $\mu$, i.e., $\tau=f(\theta$, $\mu)$. Then we can derive an equation for $\tau$ :

$$
\begin{aligned}
\tau_{t}=K \nabla^{2} \tau-u \nabla \tau-f_{\mu} \lambda \mu & -K\left[f_{\theta \theta}(\nabla \theta)^{2}\right. \\
& \left.+2 f_{\theta \mu} \nabla \theta \nabla \mu+f_{\mu \mu}(\nabla \mu)^{2}\right]
\end{aligned}
$$

If $\mu$ denotes tritium and $\theta$ denotes "stable tritium" (that is, the sum of tritium and helium 3), then one can obtain an age from the decay of tritium into helium 3 :

$$
\tau=f(\theta, \mu)=\lambda^{-1} \ln (\theta / \mu)
$$

and (3) reduces to

$$
\tau_{t}=K \nabla^{2} \tau-u \nabla \tau+1+\lambda^{-1} K\left[\left(\frac{\nabla \theta}{\theta}\right)^{2}-\left(\frac{\nabla \mu}{\mu}\right)^{2}\right]
$$

In the following sections we study the circumstances under which the time derivative term in (5) becomes negligible, i.e., the extent to which the combination of (1) and (2) to form (5) leads to a cancellation of the large and poorly known time derivative terms in (1) and (2). All the other terms in the equation can be obtained from a single realization of the field.

For the CFCs it is not as easy to derive an equation similar to (5), since the relation between the age and the CFC ratios is an empirical one. Our simulations, however, have shown that the behavior of the CFC-derived age is similar to the tritium- ${ }^{3} \mathrm{He}$ age.

Following Sarmiento et al. [1990] and a similar suggestion by Siegenthaler [1982], we define an idealized "age tracer", by the following equation:

$$
0=K \nabla^{2} \tau-u \nabla \tau+1
$$

If the boundary condition is $\tau$ (outcrop) $=0$, then $\tau$ defines a water mass age: i.e., $\tau$ is a measure of the average age since a water mass was last at the surface. Note that it follows from the diffusive term in (6) that $\tau$ is conserved with respect to mixing. We take (6) as a definition of ventilation time. The equation defines a tracer which is quite simple to use as a constraint on the flow and mixing fields in that it is in steady state, and very valuable in that with the +1 chronological aging term, it provides a direct measure of time since last contact with the surface.

Ages derived from tracers are not conserved during mixing, however, since these ages are nonlinear functions of the tracer concentrations. This can readily be seen from a comparison of (5) and (6). Equation (5) is identical with the time-dependent version of the ventilation age equation (6) with an additional term appearing on the right-hand side. The additional term suggests that the weaker the mixing is the smaller should be the deviation from the true ventilation age. Indeed, in the extreme case of no mixing, the tracer age will equal the true ventilation age wherever there is tracer present. Conversely, one might expect that the stronger the mixing is, the greater the deviation of the tracer age from the true ventilation age; however, this is not the whole story. If the relative gradients of the $\theta$ and $\mu$ fields are of equal value, then the tritium- ${ }^{3} \mathrm{He}$ age will give the true ventilation age.

Note that depending on the magnitude of the relative gradients of the tracer fields $\theta$ and $\mu$, the last term in equation (5) can be either positive or negative. Hence overestimates and underestimates of the true ventilation age can occur.

\section{The Model}

It is now reasonably well established that water mass distributions in the main thermocline are the results of vertical processes at "high" latitudes (late-winter overturning), generating distinctive water masses, and subsequent, predominantly isopycnal, flow in the interior once the water is subducted. We therefore decided to develop a twodimensional model of flow along an isopycnal surface in the thermocline. The interior time mean flow field in our experiments is given by a slight modification to Stommel's [1948] solution for a wind-driven gyre as described by Musgrave [1985]. The stream function (Figure 1) is 
STREAM FUNCTION

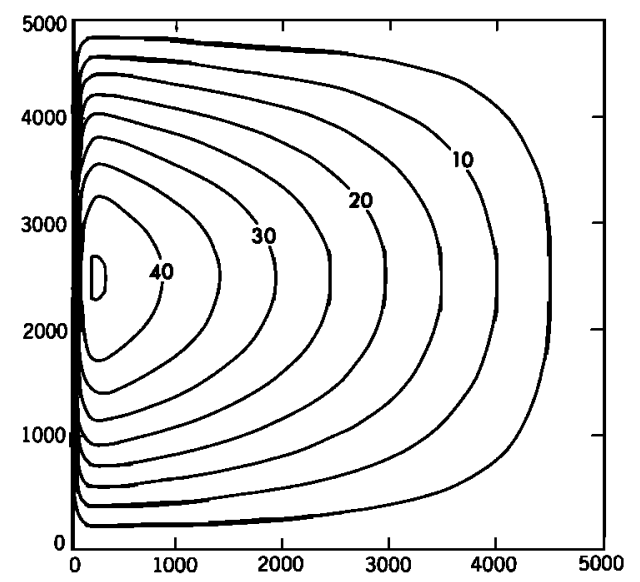

Fig. 1. Stream function for $\psi_{\max }=45 \mathrm{~Sv}$. The stream functions for the other experiments $\left(\psi_{\max }=15\right.$ and $150 \mathrm{~Sv}$ ) have the same form.

$\psi(x, y)=A \sin (\pi y / L)\left[c_{1} \exp \left(\frac{\lambda_{1} x}{L}\right)+c_{2} \exp \left(\frac{\lambda_{2} x}{L}\right)+1\right]$

where

$$
\begin{gathered}
\lambda_{1}=\frac{\left(-1+\sqrt{1+4 \pi^{2} \varepsilon^{2}}\right)}{2 \varepsilon} \\
\lambda_{2}=\frac{\left(-1-\sqrt{1+4 \pi^{2} \varepsilon^{2}}\right)}{2 \varepsilon} \\
c_{1}=\frac{1-\exp \lambda_{2}}{\exp \lambda_{2}-\exp \lambda_{1}} \\
c_{2}=-\left(1+c_{1}\right)
\end{gathered}
$$

We have chosen $\varepsilon=0.01$ for all experiments. If $\varepsilon \ll 1$, then $\varepsilon=\delta / L$, where $\delta$ is the width of the western boundary current. The width $\delta$ of the western boundary current is given as the distance from the western boundary within which the northward velocity component drops to $1 / e$ of its maximum value right at the boundary. For the parameter experiments that will be described, the maximum for the stream function had values of 15,50 , and $150 \mathrm{~Sv}$, respectively. Given a total transport of $50 \mathrm{~Sv}$, a depth scale of 1000 $\mathrm{m}$, and a length scale for the gyre of $5000 \mathrm{~km}$ (see below), a typical velocity in the gyre interior of $u=1 \mathrm{~cm} \mathrm{~s}^{-1}$ results.

The spreading of tracers on an isopycnal surface is described by the two-dimensional advection-diffusion equation:

$$
c_{t}=K \nabla^{2} c-u \nabla c-\lambda c+S
$$

The Laplacian and gradient operators act on isopycnal coordinates; $c$ is the tracer concentration, and $t$ is time. The isopycnal velocity field $u=(u, v)$ is derived from the stream function given above. $S$ represents source minus sink terms, and $\lambda$ is a radioactive decay constant. We assume that the interior flow field can be separated into a steady mean flow and time-dependent fluctuations. The latter is parameterized as an apparent eddy mixing coefficient $K$ (eddy diffusivity),
TABLE 1. Tracers Simulated

\begin{tabular}{lc}
\hline Tracer & Period of Simulation \\
\hline Tritium & $1952-1977$ \\
Helium 3 & $1952-1977$ \\
CFC-11 & $1960-1980$ \\
CFC-12 & $1960-1980$ \\
Age & run to steady state \\
\hline
\end{tabular}

Derived quantities are tritium- ${ }^{3} \mathrm{He}$ age and $\mathrm{CFC}-11-\mathrm{CFC}-12$ age.

which is assumed to be constant throughout the domain of integration. This is the second parameter varied systematically in our sensitivity experiments with values of $3 \times 10^{6}$, $10^{7}$, and $3 \times 10^{7} \mathrm{~cm}^{2} \mathrm{~s}^{-1}$. In combination with the three values for the stream function, this leads to a set of nine experiments for each tracer.

We assume that our two-dimensional square ocean model $(5000 \mathrm{~km} \times 5000 \mathrm{~km})$ reflects a typical isopycnal surface within the main thermocline of the subtropical gyre with outcropping in the northern half of the gyre. The timedependent tracer concentrations are imposed upon the flow field within the outcrop region. Changes in isopycnal thickness are ignored. The western, eastern, and southern boundaries are kept at no-flux conditions. Our choice for the southern boundary deserves some further comments.

Musgrave [1990] has used a "diffusive reservoir" at the southern boundary to account for the weak diffusive loss of tracer across the southern boundary of the subtropical gyre between the North Atlantic Central Water and South Atlantic Central Water masses [Thiele et al., 1986]. This approach works very well for transient tracers. Unfortunately, this does not hold for the age tracer, because ages in the diffusive reservoir very soon grow up to $O$ (1000 years), thus influencing the age distribution significantly. In an attempt to treat all tracers in the same way in our model, we have chosen a no-flux boundary condition for the south. Comparison between the reservoir model and the nonreservoir model shows no significant changes in transient tracer distributions.

For the numerical integration we used a donor cell scheme on a $200 \times 200$ grid. The very high resolution of the model resolves boundary layer processes and reduces numerical diffusivity. A couple of numerical experiments with pure advection, and hence only numerical diffusion, showed clearly that numerical diffusivity has a negligible impact in our experiments.

Table 1 summarizes the tracers which have been integrated in this study. Boundary conditions for each tracer are shown in Figure 2. For all tracers we assumed outcropping at the northern boundary. Hence there the characteristic tracer boundary conditions were applied.

For the age equation, the northern boundary condition is $\tau(y=L, t)=0$. This means that $\tau$ is a measure of the time which has elapsed since a water parcel has left the surface. Therefore it is justified to refer to $\tau$ as a "ventilation age." We will use this definition throughout this study, having thus specified the somewhat loose expression "ventilation."

Tritium is integrated with spatially constant surface concentrations at the northern boundary according to the tritium surface concentrations as reported by Dreisigacker and Roether [1978]. In all these experiments the daughter product of radioactive tritium, helium 3, was integrated paral- 


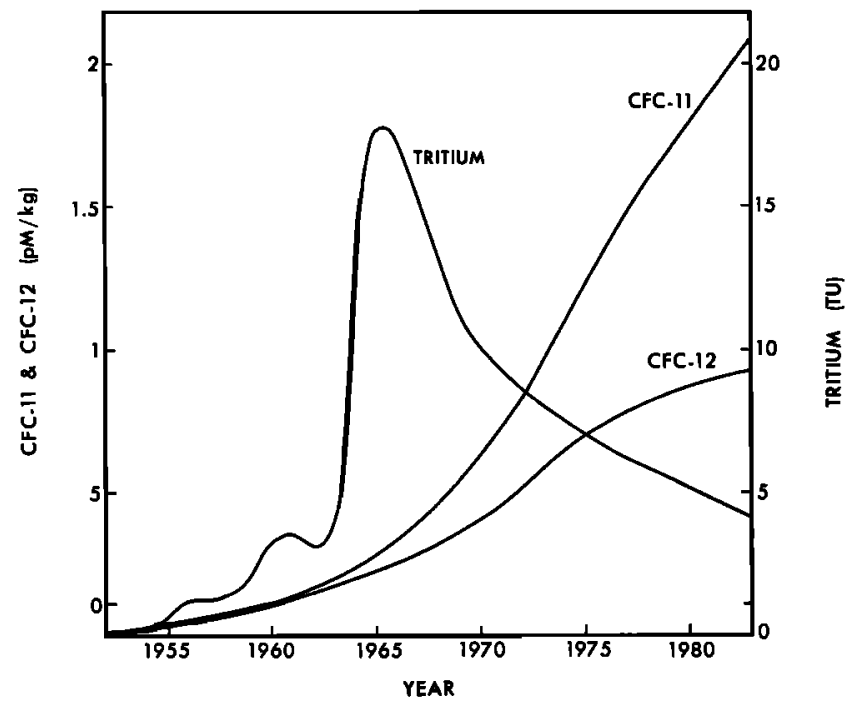

Fig. 2. Illustration of the boundary conditions for tritium, CFC11 , and CFC-12.

lelly. Helium 3 is reported in the same units as tritium throughout this study. The boundary condition for helium 3 at the outcrop is $c(y=L, t)=0$.

The surface concentrations for the CFCs were constructed using atmospheric CFC concentrations from the Atmospheric Lifetime Experiment (ALE) [Cunnold et al., 1986] and solubilities reported by Warner and Weiss [1985]. CFC time histories in the atmosphere prior to 1972 were reconstructed with CFC release data from Chemical Manufacturers Association [1985] reports normalized to atmospheric concentrations as measured by ALE [Cunnold et al., 1986].

The very first experiments used the northern boundary as an outcrop line. Figure $3 a$ shows results for an experiment calculated with values of the transport stream function and diffusivity (45 Sv and $10^{7} \mathrm{~cm}^{2} \mathrm{~s}^{-1}$, respectively) that are of the order of magnitude one would expect in the upper main thermocline. The entry of tritium onto the surface is significantly less than what is observed on shallower isopycnal surfaces in the North Atlantic [cf. Sarmiento et al., 1982]. Only with very high eddy diffusivities of $O\left(10^{9}\right.$ to $10^{10} \mathrm{~cm}^{2}$ $\mathrm{s}^{-1}$ ) do amounts of tracer comparable to the observations enter the gyre. In these cases, on the other hand, diffusion overpowers advection completely, leading to zonally oriented tracer distributions. The thermocline ventilation estimates of Sarmiento [1983], which are of the same order as the Sverdrup transport, suggest that the way out of this problem is to allow entry of tritium directly onto the streamlines in the northern part of the gyre. Therefore we ran a series of tests where we changed the outcrop line to $y=$ $0.5 L, 0.6 L, \cdots, 0.9 L$. Results are shown in Figure 3 for tritium. Even with outcropping at $y=0.9 L$, substantial amounts of tracer enter the gyre. The farther south the outcropping line, the higher is the southward velocity component, thus leading to stronger "ventilation" of the gyre. For the parameter study in our model we have chosen the outcrop at $y=0.7 * L$ (Figure $3 d$ ). Tritium shows for this case a rather uniform distribution such as that observed in the upper main thermocline [Sarmiento et al., 1982]. A plume of low tritium values entering from the western boundary coincides with the streamline which just touches the outcrop area. In the southern part of the gyre a frontlike feature develops with high meridional tracer gradients.

We have examined the tracer distribution that develops with a smaller gyre with a scale of $2000 \mathrm{~km} \times 2000 \mathrm{~km}$. The results for the set of parameter experiments summarized in Table 2 are shown in Figure 4. A greater portion of the gyre is now filled with tracer. However, the homogeneous pool now occurs in the west with an unrealistic gradient parallel to the eastern boundary, and if there is a tracer gradient at the southern boundary its direction is reversed; i.e., higher concentrations are at the boundary, lower concentrations in the interior. All these features, which we also obtain with the model illustrated in figure $3 a$ if it is allowed to run out further in time, are not observed in reality [Sarmiento et al., 1982]. Musgrave's [1990] approach of attaching a diffusive reservoir at the southern boundary would give more realistic tracer distributions in a small gyre. As was discussed already in section 2 the model with the reservoir in the south is not appropriate for the age tracer. For this reason we decided to use the original version of the model (length scale of 5000 $\mathrm{km}$ ) with an outcrop line at $y=3500 \mathrm{~km}$.

\section{RESUlts}

Figures 5 to 12 show distributions for tritium and helium 3 after 25 years of integration (corresponding to 1977), CFC-11 after 20 years of integration (corresponding to 1980) and steady state ventilation age distributions. Each figure contains nine plots according to the nine possible combinations of the free parameters in our model which are summarized in Table 2. Total transport is kept constant in each row, with the smallest transport in the top row, and the largest in the bottom row. Diffusivities are constant in each column. Smallest diffusivities are in the left column, highest in the right column.

Tritium distributions (Figure 5) again show the importance of advection in the ventilation of the gyre. Experiments with total transport of $15 \mathrm{~Sv}$ show mainly zonally oriented distributions with meridionally decreasing concentrations. No front develops in the south, simply because there is not enough tracer penetration. As we go to a total transport of 50 Sv a fairly homogeneous region with concentrations between 6 and 7 tritium units (TU) develops in the eastern part of the gyre. With the exception of the highly diffusive case a strong front parallel to the southern boundary appears. When the diffusivity is $3 \times 10^{7} \mathrm{~cm}^{2} \mathrm{~s}^{-1}$, the tracer plume at the western boundary and the southern front are smeared out. In the high advective cases, concentrations are essentially uniform between 6 and 6.5 TU. No front occurs along the southern boundary.

Helium 3 (Figure 6) is generated by decay of tritium and released into the atmosphere at the outcrop. Concentrations of helium 3 should thus be low at the outcrop and in regions where tracer has not succeeded in penetrating. In experiments 1 through 5, tritium penetration is low along the southern and western boundaries (Figure 5). One therefore sees in this model a minimum in helium 3 along these boundaries as well as at the outcrop and consequently a maximum which is in the central part of the gyre abutting the eastern boundary in experiments 1, 2, and 3 and which moves toward the south in the more advectively dominated experiments 4 and 5 (Figure 6). This maximum in helium 3 is observed in nature as well [Jenkins, 1980; Thiele et al., 1986]. 


\section{TRITIUM IN 1977 FOR VARIOUS OUTCROP POSITIONS}

\section{(TU)}
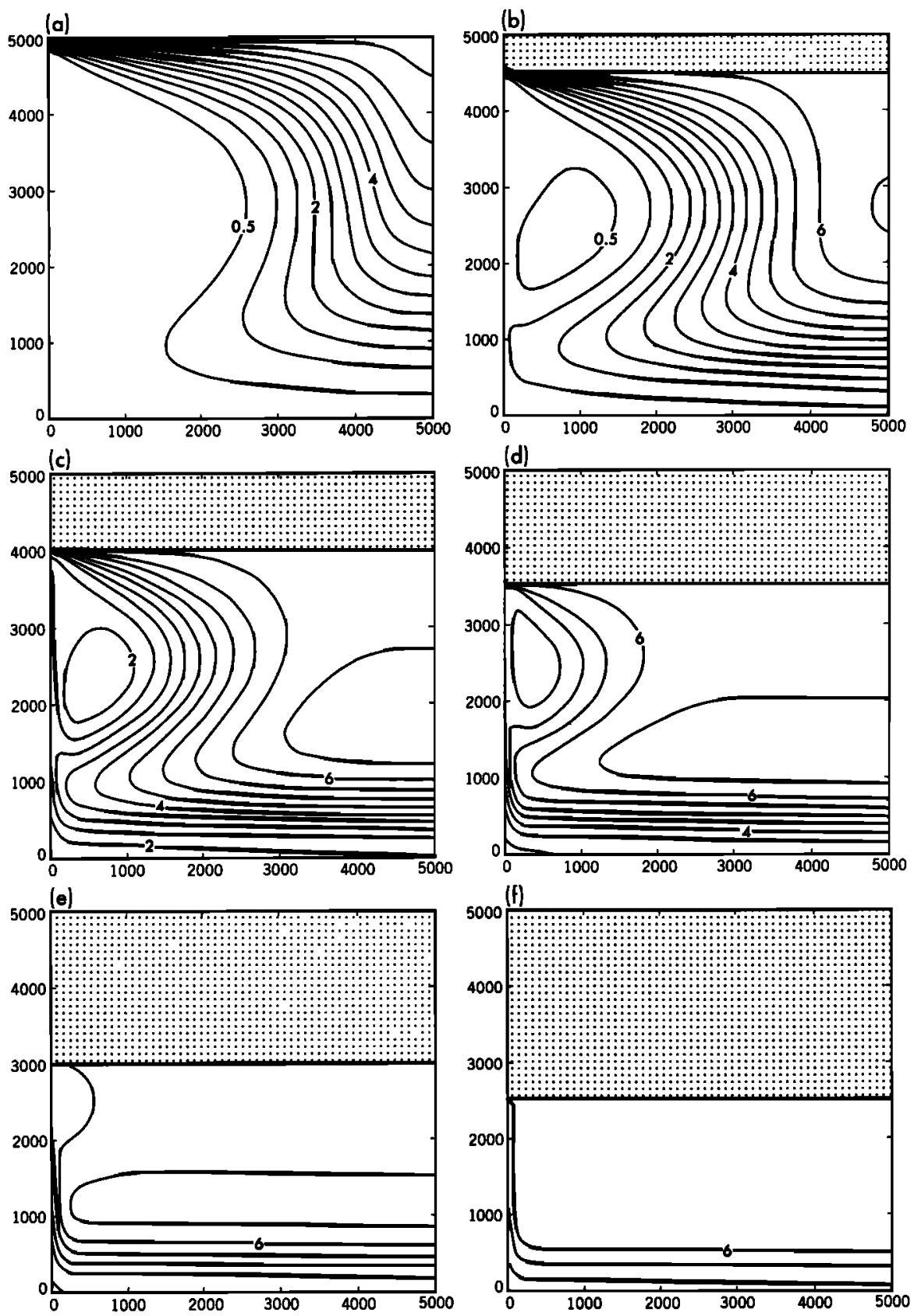

Fig. 3. Results of tritium experiments with $\psi_{\max }=45 \mathrm{~Sv}$ and $K=10^{7} \mathrm{~cm}^{2} \mathrm{~s}^{-1}$ for various outcrop positions at (a) $y=L,(b) y=0.9 L,(c) y=0.8 L,(d) y=0.7 L,(e) y=0.6 L$, and $(f) y=0.5 L$. The tracer distributions that most closely resemble the observations are those with the outcrop south of $y=4000 \mathrm{~km}$ (Figures $3 c$ and $3 d$ ). The tracer penetration can be increased in Figures $3 a$ and $3 b$ by increasing the mixing; however, the tracer distributions are unrealistic in that they are primarily zonal without the large homogeneous pool in the central part of the gyre that is usually observed [Sarmiento et al., 1982].

CFC distributions (Figure 7) are mostly zonally oriented, showing decreasing concentrations toward the south in all experiments. A plumelike feature at the western boundary is found in several experiments, as with tritium, but the interior distribution of the tritium is much more uniform than that for CFC. This follows from the different boundary conditions for the two tracers. The flux of tritium into the oceans of the northern hemisphere occurred primarily in a 3-year period
TABLE 2. Experiments Carried Out for Each Tracer

\begin{tabular}{rccc}
\hline & \multicolumn{3}{c}{ Experiment Number } \\
\cline { 2 - 4 }$\psi_{\max }$, & $\begin{array}{c}K=3 \times 10^{6} \\
\mathrm{~cm}^{2} \mathrm{~s}^{-1}\end{array}$ & $\begin{array}{c}K=10^{7} \\
\mathrm{~cm}^{2} \mathrm{~s}^{-1}\end{array}$ & $\begin{array}{c}K=3 \times 10^{7} \\
\mathrm{~cm}^{2} \mathrm{~s}^{-1}\end{array}$ \\
\hline 15 & 1 & 2 & 3 \\
50 & 4 & 5 & 6 \\
150 & 7 & 8 & 9 \\
\hline
\end{tabular}


TRITIUM IN 1977

(TU)
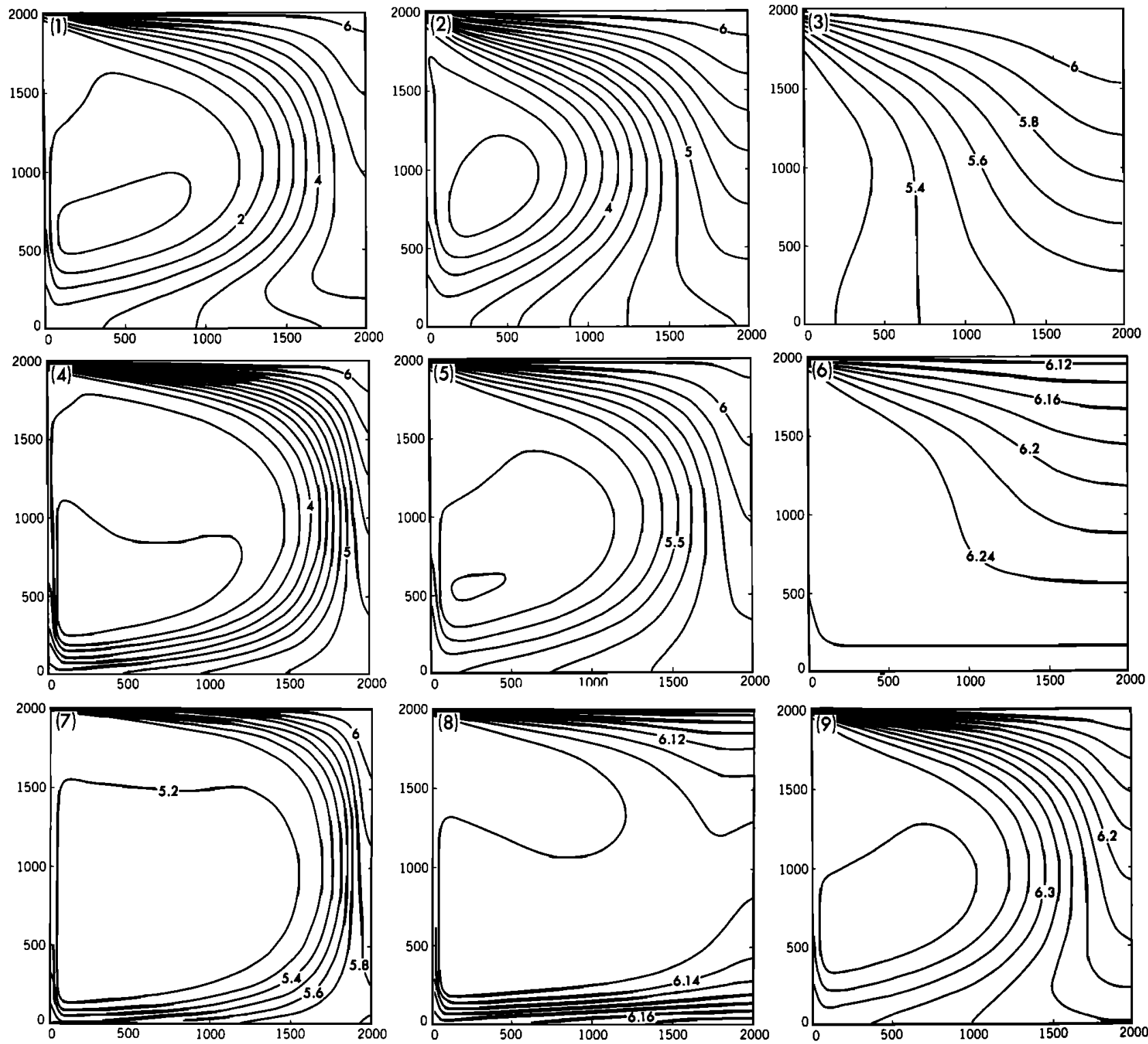

Fig. 4. Series of tests run with a $2000 \mathrm{~km} \times 2000 \mathrm{~km}$ basin. The parameter combinations for the various experiments are shown in Table 2 . The $2000 \times 2000 \mathrm{~km}$ basin tracer distributions are unrealistic in several respects, as discussed in the text.

centered on 1963 [Weiss and Roether, 1980]. The slow decrease in the surface concentration illustrated in Figure 2 is due to spreading into the thermocline. Without a flux at the surface to maintain a high concentration, the tritium has had plenty of time to spread out uniformly within the gyre, gradually diluting the surface. The concentration of CFCs in the atmosphere, on the other hand, has increased nearly exponentially in the atmosphere, thus maintaining a steadily increasing concentration at the surface and defeating the efforts of the ocean to dilute the surface and mix the tracer uniformly throughout the thermocline.

Ventilation age distributions (Figure 8) all show maxima along the southern boundary. Values, however, differ considerably from roughly 50 years in experiment 1 to only about 5 years in experiment 9 . When the diffusivity is relatively small, i.e., if the Peclet number $P$ is equal to $u L / K$
$>50$ as in experiments $1,4,5$, and 7 to 9 , an isolated relative maximum occurs where the stream function has its maximum. The reason for this feature is that at the stagnation point of the gyre, ventilation occurs only by diffusion. Hence a small diffusivity leads to weak ventilation or a relative maximum in ventilation age.

Figure 9 shows the tritium- ${ }^{3} \mathrm{He}$ age computed from the tracer distributions shown in Figures 5 and 6 . It is no surprise that in experiments with small advection (uppermost row) the tritium- ${ }^{3} \mathrm{He}$ age is a rather bad approximation for the ventilation age. Figure 8 shows that for these experiments maximum ventilation age values of 30 to 50 years occur, thus exceeding the integration time of only 25 years for tritium and helium 3 . In experiments 4 to 9 the similarity is rather striking. Note that tritium- ${ }^{3} \mathrm{He}$ ages display very accurately the plumelike feature in mid-latitudes near the 


\section{TRITIUM IN 1977}

(TU)
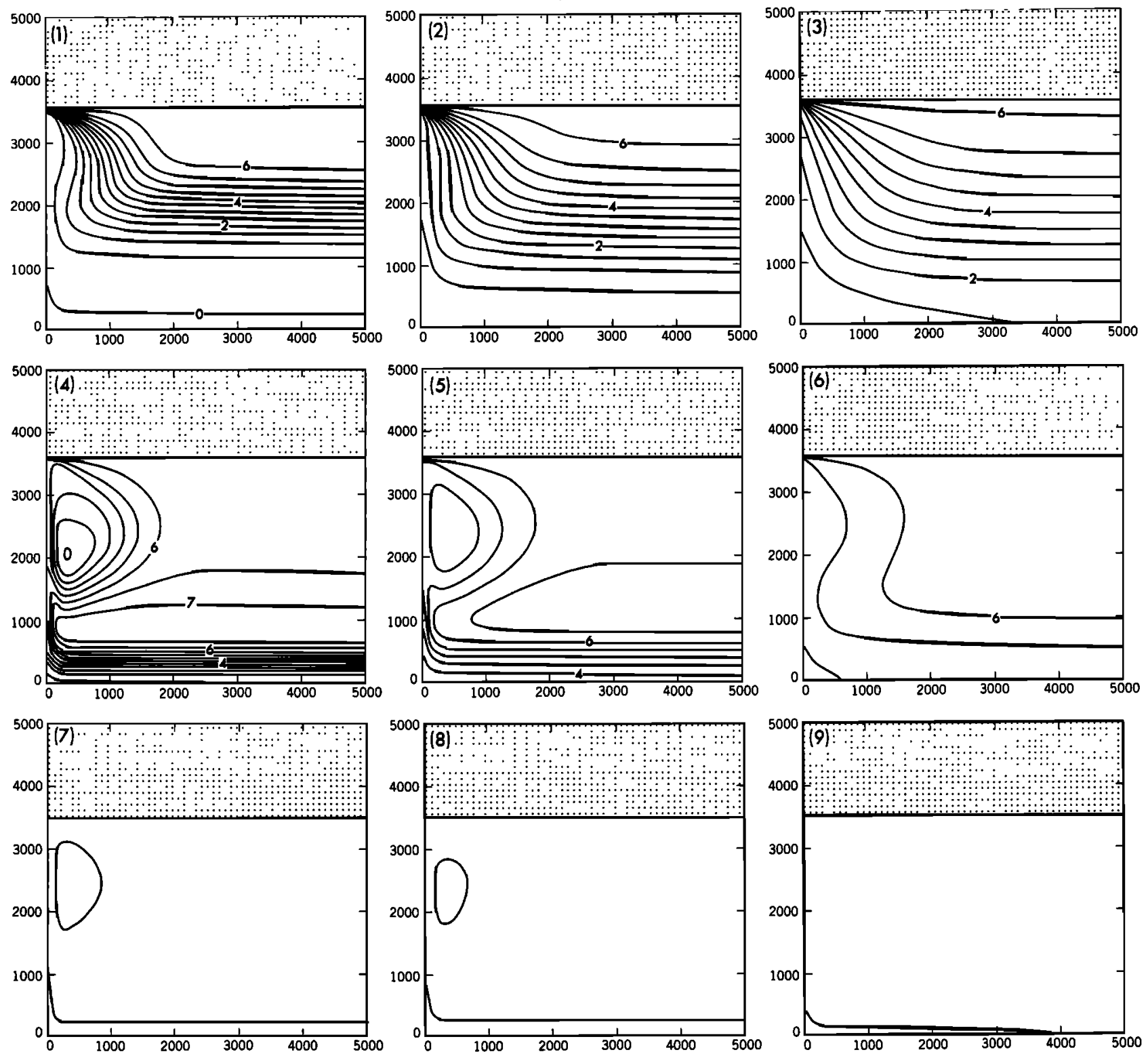

Fig. 5. Tritium distribution in 1977 after a 25 -year run. The parameter combinations for the various experiments are shown in Table 2 . The shaded region is outcropping and has the boundary conditions of Figure 2 imposed on it. Experiments are as follows: experiment $1, \psi_{\max }=15 \mathrm{~Sv}, K=3 \times 10^{6} \mathrm{~cm}^{2} \mathrm{~s}^{-1}$; experiment $2, \psi_{\max }=15 \mathrm{~Sv}, K=10^{7}$ $\mathrm{cm}^{2} \mathrm{~s}^{-1}$; experiment $3, \psi_{\max }=15 \mathrm{~Sv}, K=3 \times 10^{7} \mathrm{~cm}^{2} \mathrm{~s}^{-1}$; experiment $4, \psi_{\max }=50 \mathrm{~Sv}, K=3 \times 10^{6} \mathrm{~cm}^{2} \mathrm{~s}^{-1}$; experiment $5, \psi_{\max }=50 \mathrm{~Sv}, k=10^{7} \mathrm{~cm}^{2} \mathrm{~s}^{-1}$; experiment $6, \psi_{\max }=50 \mathrm{~Sv}, K=3 \times 10^{7} \mathrm{~cm}^{2} \mathrm{~s}^{-1}$; experiment $7, \psi_{\max }$ $=150 \mathrm{~Sv}, K=3 \times 10^{6} \mathrm{~cm}^{2} \mathrm{~s}^{-1}$; experiment $8, \psi_{\max }=150 \mathrm{v}, K=10^{7} \mathrm{~cm}^{2} \mathrm{~s}^{-1}$; experiment $9, \psi_{\max }=150 \mathrm{~Sv}, K=$ $3 \times 10^{7} \mathrm{~cm}^{2} \mathrm{~s}^{-1}$.

western boundary, and that absolute values are very close to the ventilation age, especially in the eastern part of the gyre where the tritium distribution is already rather homogenized. This can be seen also from Figure 10 which shows the ratios of tritium- ${ }^{3} \mathrm{He}$ ages over ventilation ages. Whereas the ratio is far from unity in the first three experiments, it is within $20 \%$ of unity for most parts of the gyre in experiments 4 to 9 .

Water mass ages computed from the CFC ratio and their ratios to the true ventilation ages are shown in Figures 11 and 12. In general, CFC ages show less resemblance with the true ventilation ages than the tritium- ${ }^{3} \mathrm{He}$ age does. The reason for this will be discussed in the following section.

\section{Discussion}

We now examine the extent to which the combination of two tracer conservation equations to form an age equation can lead to a cancellation of the time derivative terms. Figure 8 shows that for experiments 1 to 3 , the true ventilation ages are much higher than the time of integration (here, 25 years) for the tracer simulations. Obviously, in these cases one cannot expect that any tracer-derived ages will be in steady state. However, for the medium and high advection cases (experiments 4 to 9), maximum ventilation ages of 6 to 16 years occur; and we find that despite the fact that the 


\section{HELIUM-3 1977}

(equivalent TU)
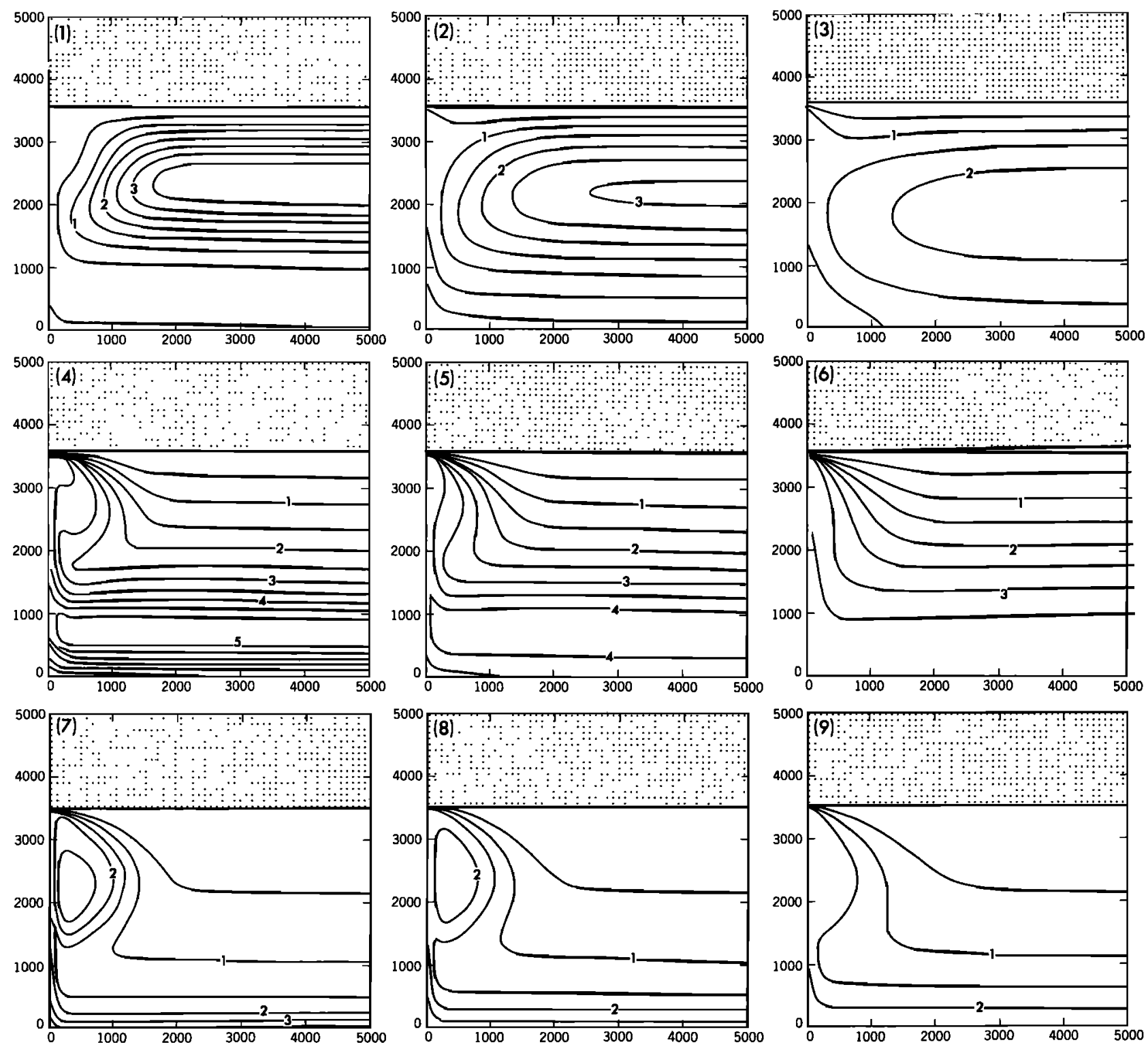

Fig. 6. Helium 3 calculated with the tritium experiments in Figure 5. The outcrop boundary condition for helium 3 is that it be equal to 0 . The shaded region is outcropping. The parameter combinations for the various experiments are shown in Table 2.

tracer distributions are changing in time, the tracer-derived ages are close to steady state. This encouraging result suggests that the use of tracer-derived age equations may indeed be a useful way of getting around the difficulty of reconstructing the time-dependent terms and boundary conditions of transient tracers in regions where the ventilation time is less than the time since significant tracer entry to the ocean began.

In the following discussion of experiments 4 to 9 we neglect completely the time-dependent terms and consider only the effect of mixing on the relationship between tracerderived ages and true ventilation ages. Tritium- ${ }^{3} \mathrm{He}$ ages give rather good approximations to the true ventilation ages for experiments 4 to 9 , particularly in the northeastern portion of the gyre for experiments 4 to 6 and for the whole gyre in experiments 7 to 9 . Why is this so? The key to understanding the relationship between ventilation age and tritium ${ }^{3}-\mathrm{He}$ age, in regions where the latter is in steady state, is the last term on the right-hand side of (5). If the relative gradients of the $\theta$ and $\mu$ fields are of equal value, or if both are very small, then the tritium- ${ }^{3} \mathrm{He}$ age will give the true ventilation age (recall that $\theta$ denotes the sum of tritium and helium 3 , and $\mu$ denotes tritium). Consideration of the tritium field in Figure 5 shows that it is essentially homogeneous over the entire region where agreement between the tracer-derived ages and true ages is good. The relative gradient of tritium is thus quite small. The sum of the tritium field with the helium 3 field of Figure 6 is not so homoge- 


\section{CFC-11 IN 1980 (pmoles/l)}
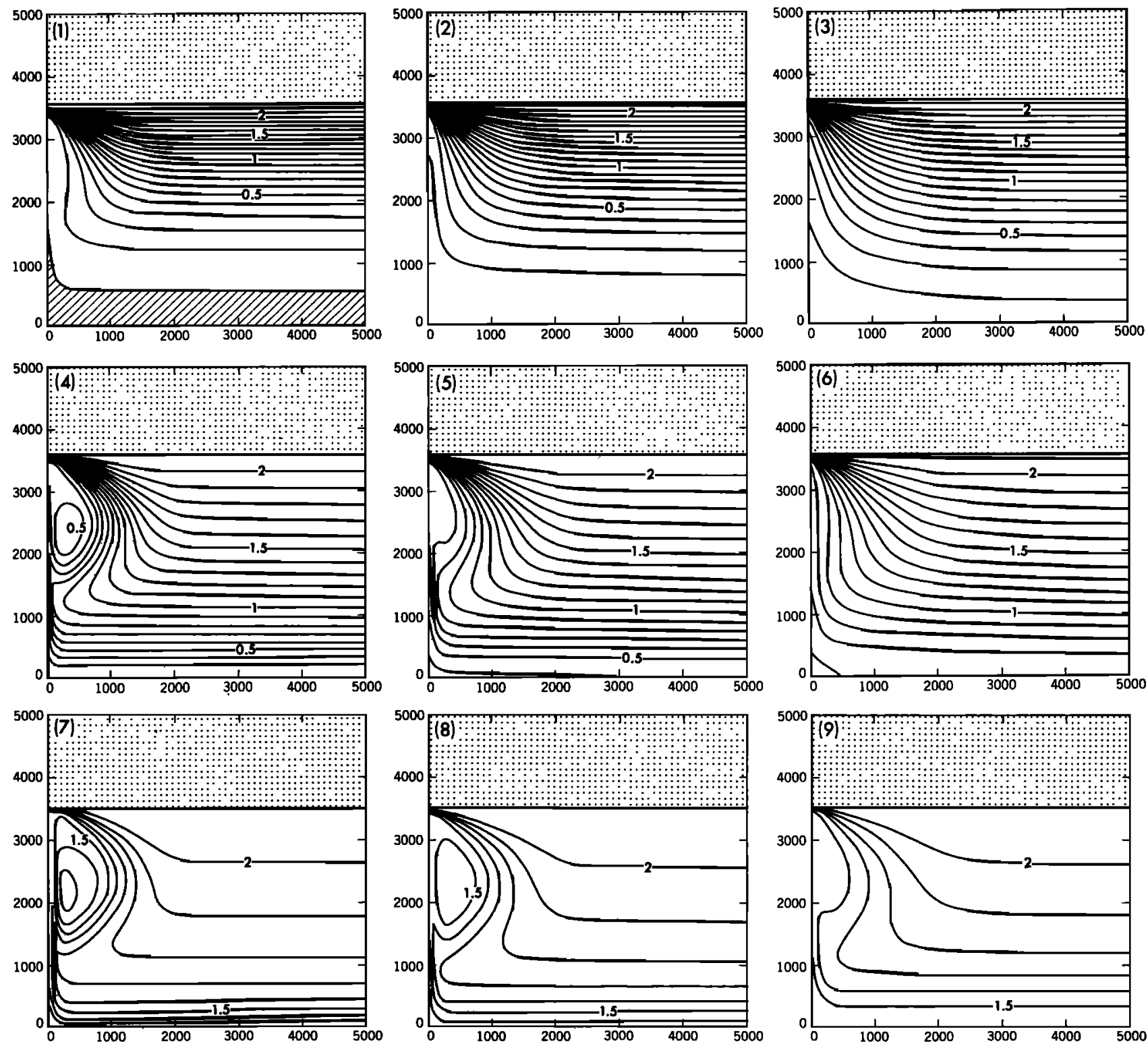

Fig. 7. CFC-11 in 1980 calculated with the boundary conditions in Figure 2. See Figure 5 for further explanation.

neous, but the helium 3 concentrations are low enough that the relative gradient of the $\theta$ field remains negligible. These arguments break down in the southern boundary and western region of the gyre in experiments 4 to 6, where tritium as well as helium 3 have large gradients, and where the helium 3 becomes a much more significant portion of the $\theta$ field. In these locations the tritium- ${ }^{3} \mathrm{He}$ ages diverge significantly from the true ages.

In order to understand the sensitivity of the relationship between the tritium- ${ }^{3} \mathrm{He}$ ages and the true ventilation age to changes in advection and mixing, it is useful to consider the nature of the tracer inflow processes from the outcrop. We can define two different inflow or ventilation regimes: an advectively dominated region in the eastern part, where direct advective ventilation occurs (i.e., the $v$ component of the velocity field has large negative values), and a diffusively dominated region in the "plume" area, where the major entry mechanism is by upstream mixing or mixing across streamlines. As mentioned in section 4, a plume of low tritium values appears at the western boundary. Ventilation age and CFC distributions show the same feature. The core of this plume is contained within the streamline which grazes the outcrop line, though the plume extends out beyond the streamline. The only mechanism for entry into the closed streamline region is by mixing across the streamlines. The advectively ventilated area corresponds to the ventilated region of Luyten et al. [1983], and the diffusively dominated area corresponds to their pool region.

The response to increased mixing in the plume region is directly opposite to the response in the rest of the gyre. The majority of the gyre shows increasing divergence of the tritium- ${ }^{3} \mathrm{He}$ age from the true age as one goes from the low-mixing experiment, 4 , to the high-mixing experiment, 6 (Figure 10). This is also the case in experiments 7 through 9 , 

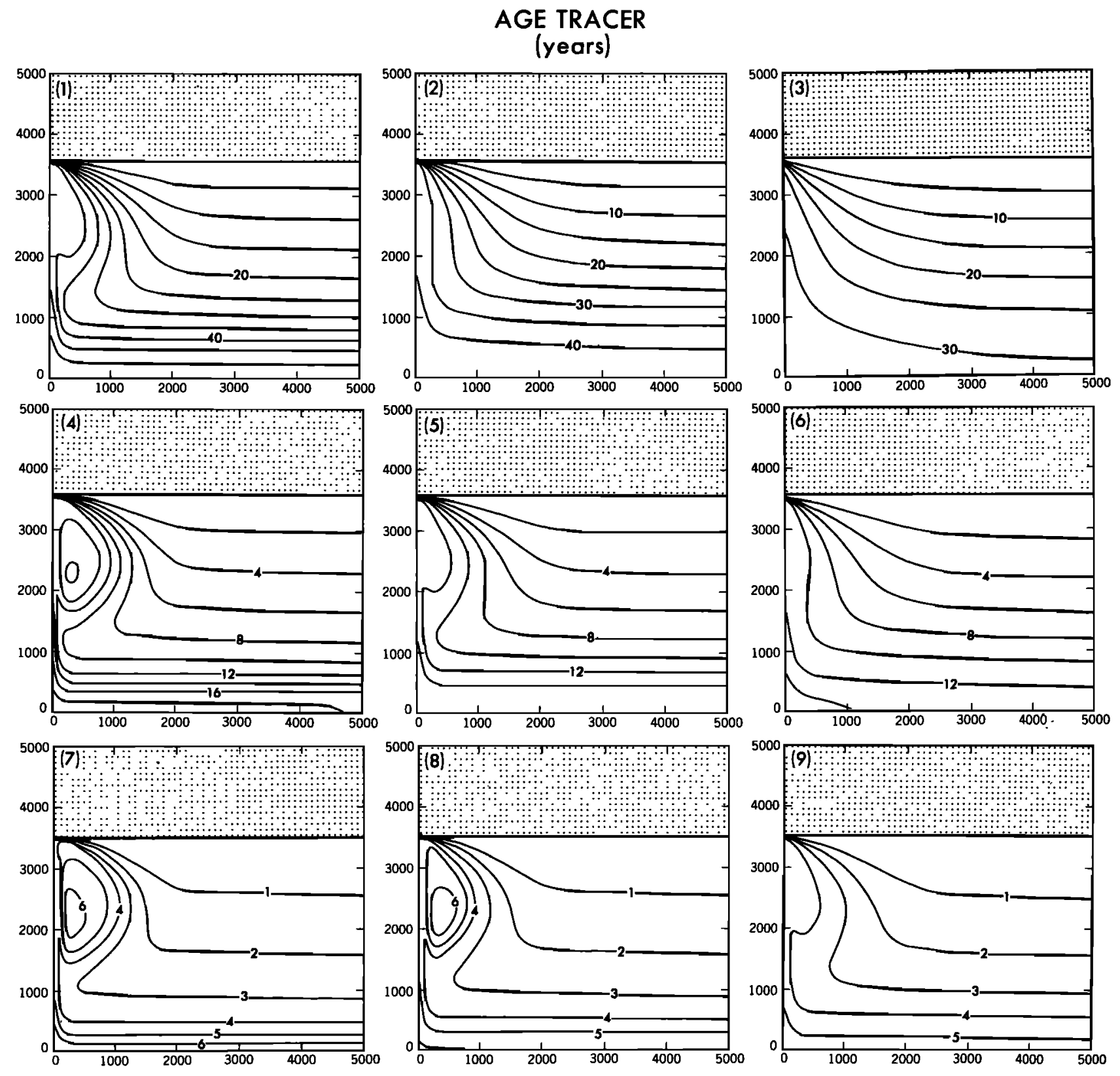

Fig. 8. Equilibrium age calculated from (6) with age set to 0 at the outcrop. See Figure 5 for further explanation.

though the change is difficult to discern with the contour interval used in Figure 10. Such an increase might be expected from the nature of the last term on the right-hand side of (5). On the other hand, the plume region in the western part of the gyre shows decreasing divergence with increased mixing. Figures 5 and 6 indicate that tritium and helium 3 concentrations in the "plume" area are more homogeneous for larger diffusivities. According to (5), this could explain why high diffusivities give better age ratios in this region. The higher diffusion drives the "plume" region to being more like the rapidly ventilated advectively dominated region, thus increasing the ratio closer to the value of 1 found in the advectively dominated region.

Sarmiento et al. [1990], investigated tracer ages with a simple pipe model. They showed that, for a velocity of $u=$ $1 \mathrm{~cm} \mathrm{~s}^{-1}$ at the inflow boundary, the tritium- ${ }^{3} \mathrm{He}$ ratio age over ventilation age depends only weakly on the value of the diffusivity. The ratio should be between 1 and 1.1 with lower values for lower diffusivities. This can be compared with our experiments 4,5 , and 6 (given a total transport of $50 \mathrm{~Sv}$, a gyre length scale of $5000 \mathrm{~km}$, and a gyre depth scale of 1000 $\mathrm{m}$, we derive a typical velocity $u=1 \mathrm{~cm} \mathrm{~s}^{-1}$ ). In the eastern part of the gyre, the results are in excellent agreement with the pipe model. If we follow a specific streamline on its way further around the gyre both models predict that the ratio will diminish and that the deviation will be larger for the high diffusive cases.

So far, we have focused on ages derived from the tritium${ }^{3} \mathrm{He}$ pair. Age estimates based on the CFC ratio show generally much less agreement with the true ventilation age than those based on tritium and helium 3 (compare Figures 10 and 12) in regions where the true ventilation age is small, i.e., $<5$ years. The major reason that this occurs is that after 1975 , that is for the last 5 years of CFC integration, the CFC 


\section{TRITIUM-HELIUM -3 AGE (years)}
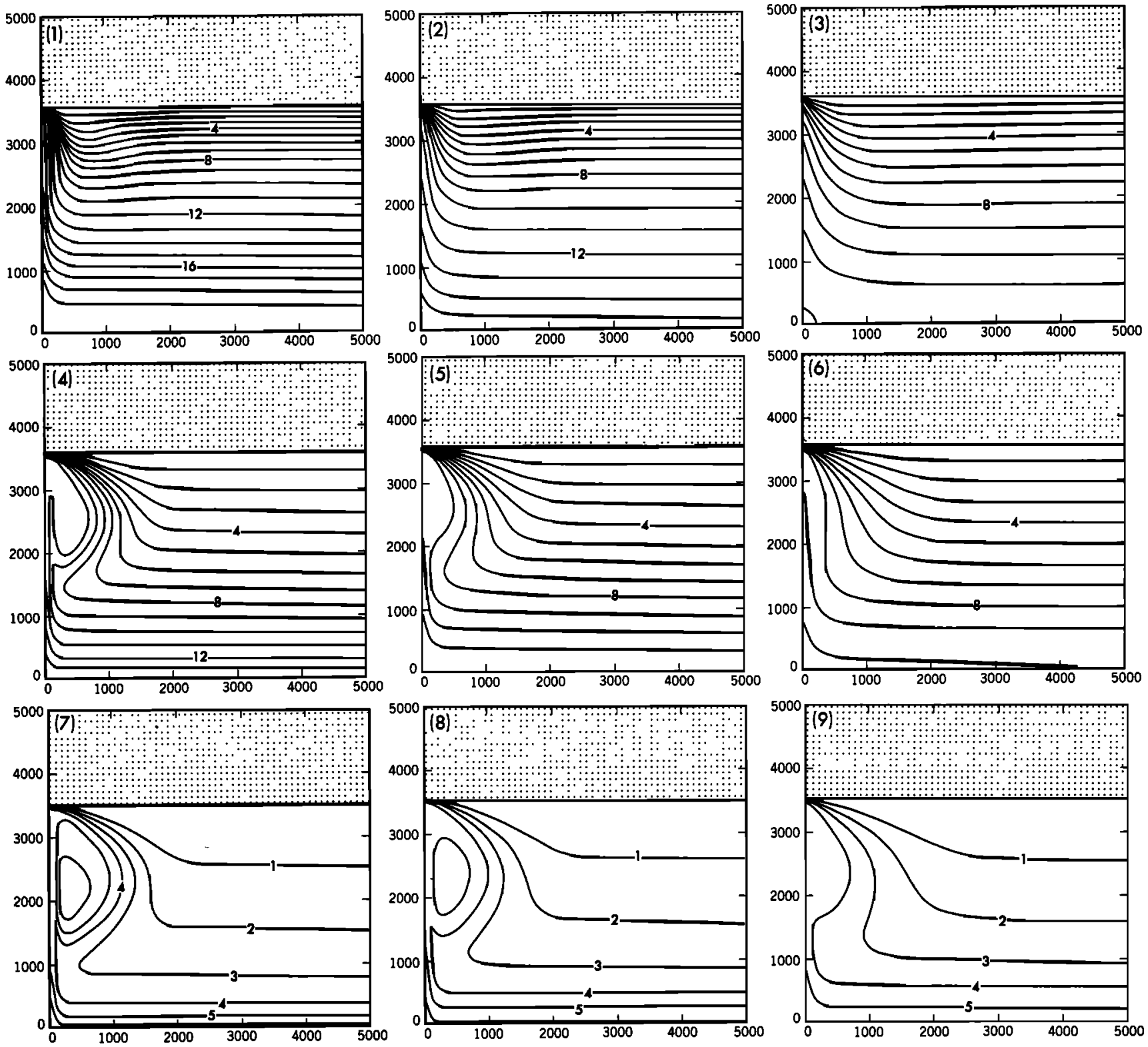

Fig. 9. Tritium $-{ }^{3} \mathrm{He}$ age calculated from (4) using the results shown in Figures 5 and 6. See Figure 5 for further explanation.

ratio of surface waters remains essentially constant. Additionally, the CFC distributions, because they are far less homogeneous than those of tritium and "stable tritium" (compare Figures 5 and 7), are more sensitive to mixing. The inhomogeneity is due primarily to the different boundary conditions of the two tracers as discussed in section 4 (see also Figure 2).

Note that close to the outcrop the ratio between CFC ages and the true ventilation age can be larger than unity. This is because the CFC ratio was constant during the last year of integration. In general, the accuracy of the model calculation is great enough that there is no problem in determining ages from the model results. But in reality the measurement errors are great enough that no age can be determined for water masses that left the surface since 1975 . These, how- ever, fill already a considerable part of the gyre in experiments 4 to 9 as can be seen from the ventilation age distribution (Figure 8). In this context, the use of new tracers such as CFC-113 [Wisegarver and Gammon, 1988] should prove very useful.

We have investigated a variety of different formulations of the model. We ran experiments with a flux boundary condition for tritium, or with different outcrop lines. Although the details of the results change, the general results as discussed above remained robust against such variations.

\section{Conclusions}

We have addressed in an indirect way the central problem of how to make use of multiple transient tracer observations 
TRITIUM-HELIUM- 3 AGE/AGE
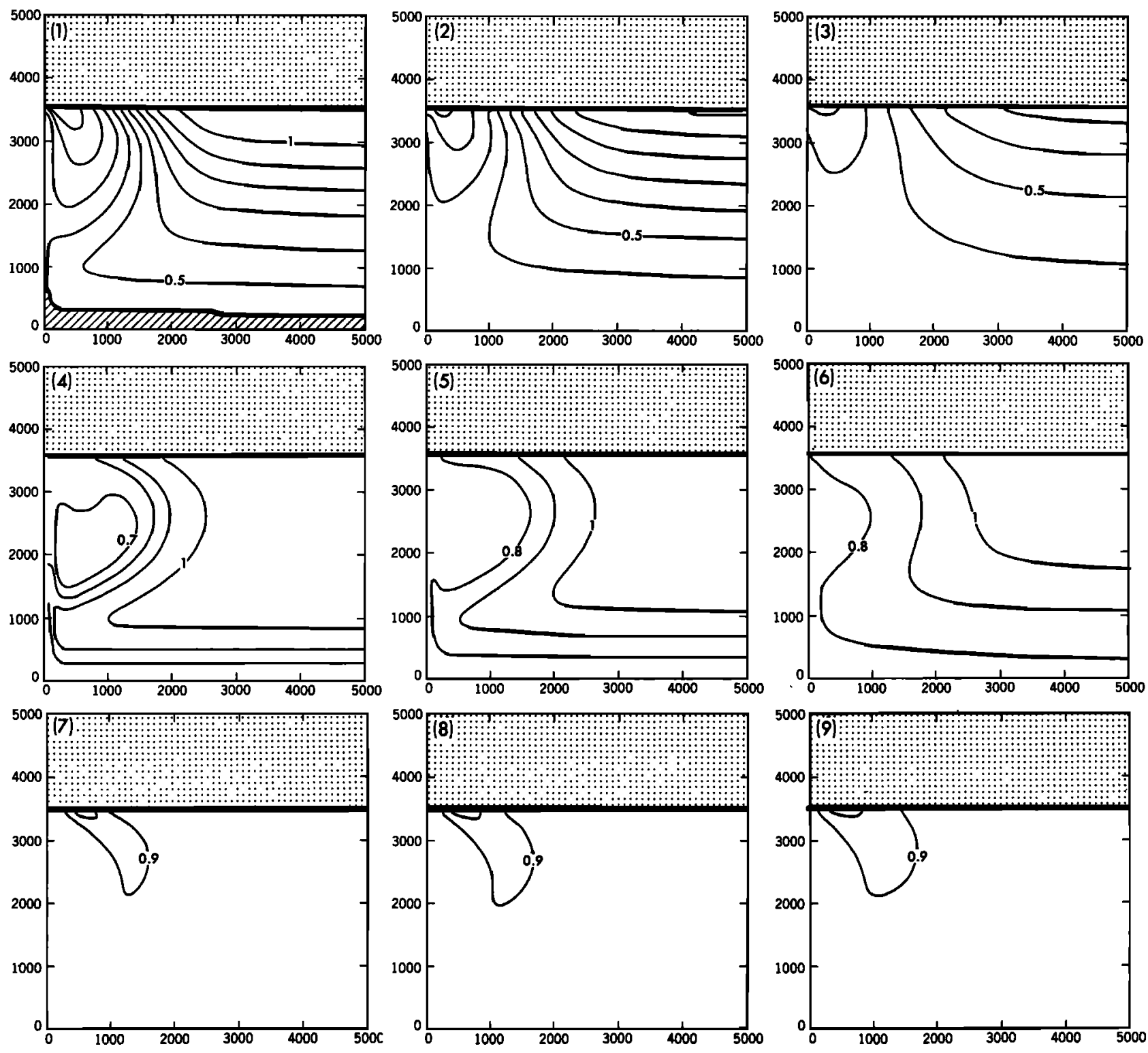

Fig. 10. The ratio of tritium- ${ }^{3} \mathrm{He}$ age (Figure 9) to the idealized age tracer (Figure 8). See Figure 5 for further explanation.

to infer ocean circulation and mixing rates, despite difficulty in reconstructing time rates of change and source functions. From a mathematical point of view, what we seek to do is combine conservation equations from two or more conservative tracers in such a way as to eliminate or minimize the terms that we know the least about, namely, the time derivatives, and to simplify the boundary conditions. If we assume that something like a long-term average circulation field exists, than we can readily define a steady state ventilation age. Our approach is to explore whether the ages that can be obtained from combinations of transient tracers are in good agreement with this steady state ventilation age.

Our study shows that over much of the subtropical gyre main thermocline it seems to be possible to get reasonable estimates of the ventilation age from the tritium- ${ }^{3} \mathrm{He}$ distribution. Moreover, we have gained some understanding of the circumstances under which this holds. In advectively dominated regions such as the eastern part of the subtropical gyre, age estimates derived from transient tracers agree over a wide parameter range within $10 \%$ with the true steady state ventilation age. Our results show that larger diffusivities generally imply larger deviations from the ventilation age except in the more diffusively dominated regions, like the plume area in the western part of the gyre where the direct advective inflow is small. In the case of the tritium $-{ }^{3} \mathrm{He}$ age one can see from (5) that if the relative gradients of both tracer fields are of equal value, the diffusivity has a minor impact on the age estimate. This allows us, in principle, to use this tracer-derived age as the true ventilation age and determine information about the velocity field and the diffusivity from the steady state equation for the ventilation age, i.e., (6). The key to this approach is the fact that the boundary conditions simplify to $\tau=0$, and the time derivative terms of the independent tracers, which are in fact quite 


\section{CFC AGE (years)}
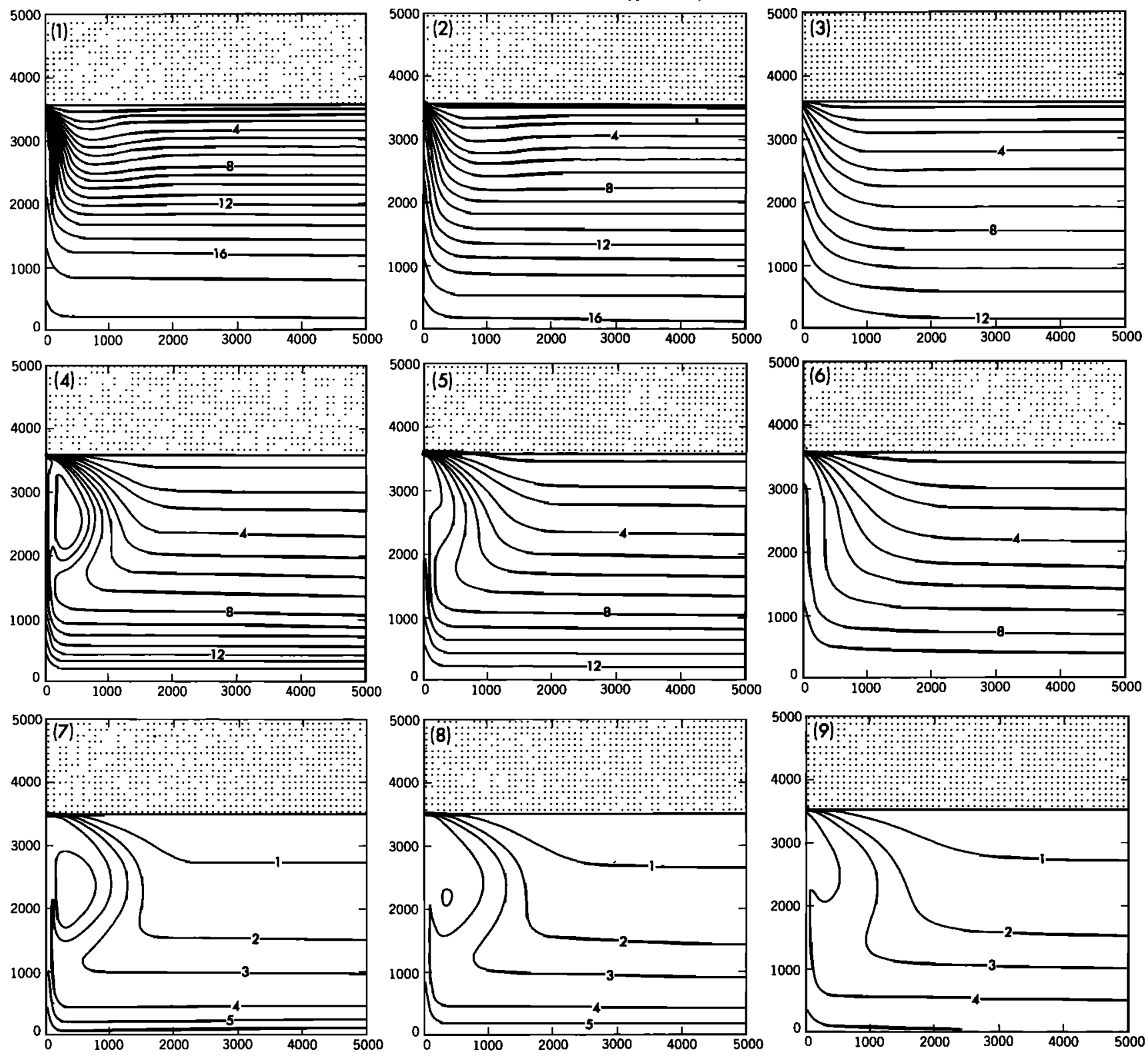

Fig. 11. Age calculated from the time evolution of the CFC-11 to CFC-12 ratio in the outcrop region as calculated from the boundary conditions shown in Figure 2. See Figure 5 for further explanation.

large, combine together when transformed to an age equation in such a way as to cancel, thus giving an equation which is essentially in steady state.

The CFC-11 to CFC-12 ratio is not as useful for obtaining ventilation age estimates, partly because the CFC age is more sensitive to mixing, since the CFC distributions have larger gradients than the tritium distributions. The nearconstancy of the CFC-11 to CFC-12 ratio in the atmosphere since 1975 also makes it difficult to use in regions of the ocean that have received tracer since then, although the new tracer CFC-113 offers considerable promise in this regard [Wisegarver and Gammon, 1988].

Our study is of relevance to the oxygen utilization rate estimates of Jenkins [1977, 1980, 1982, 1987], and to advection estimates such as that of Weiss et al. [1985]. The assumption that lies behind the work of Jenkins is essentially that the tritium ${ }^{3} \mathrm{He}$ age is equivalent to the idealized ventilation age tracer. The mean ventilation age of a given water parcel with respect to the surface, when divided into the apparent oxygen utilization, will give an average oxygen utilization rate for that parcel. The comparison of (5) and (6) shows that Jenkins' approach will only be incorrect if the nonconservative mixing terms in (5) are large. Our model study, as well as Jenkins' [1987] and Fuchs' [1987] own estimates of these terms, suggests that they are small within the well-ventilated region of the main thermocline.

Weiss et al. [1985], on the other hand, are in effect using (6) with the mixing term thrown out, i.e., $u \Delta \tau=1$. An age, in this case, then gives simply the distance traveled, divided by the velocity. Any mixing at all, or any nonsteady state behavior, will result in an error; unless, of course, the mixing occurs with water that has no CFCs in it, which is what 


\section{CFC AGE/AGE}
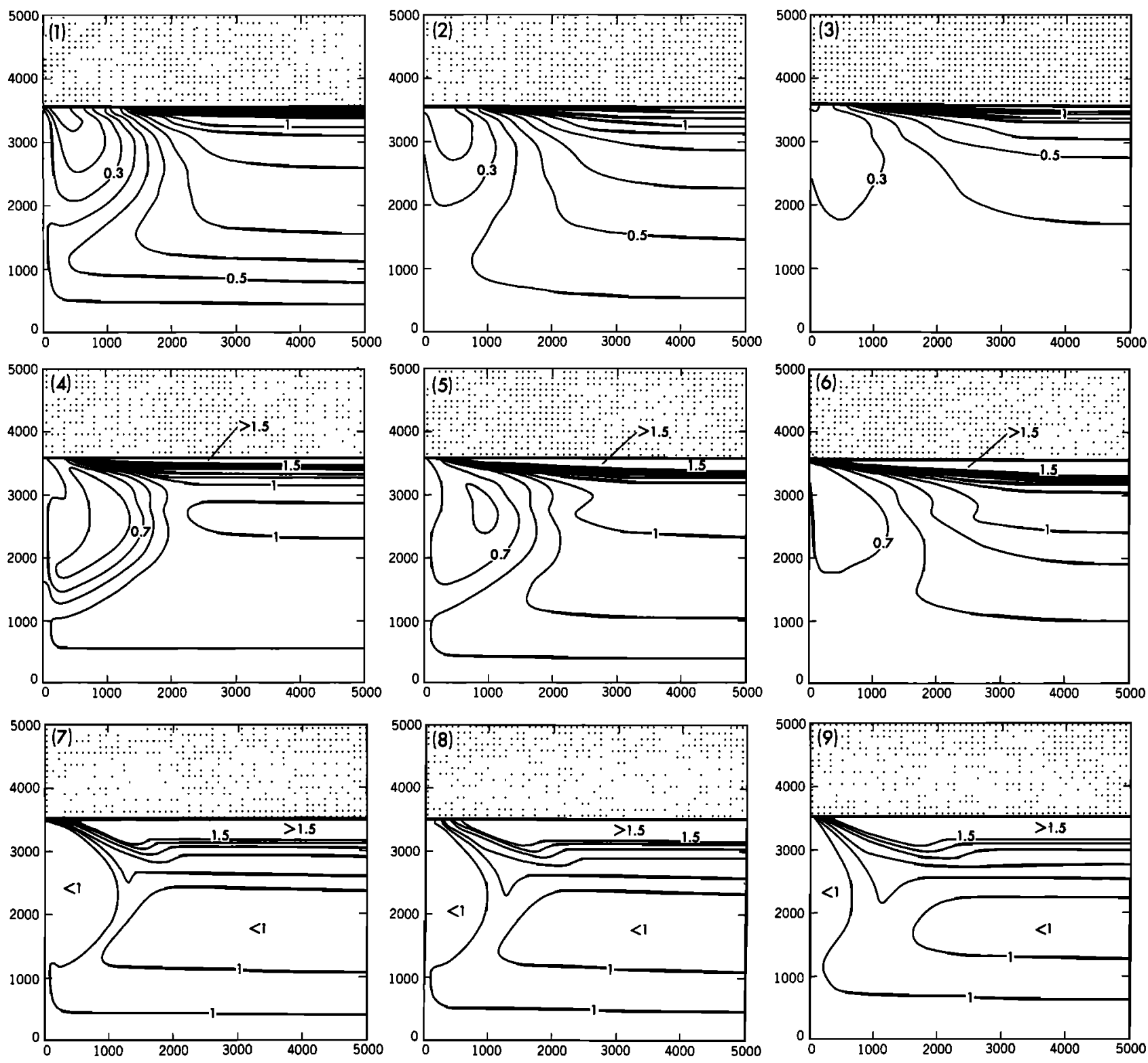
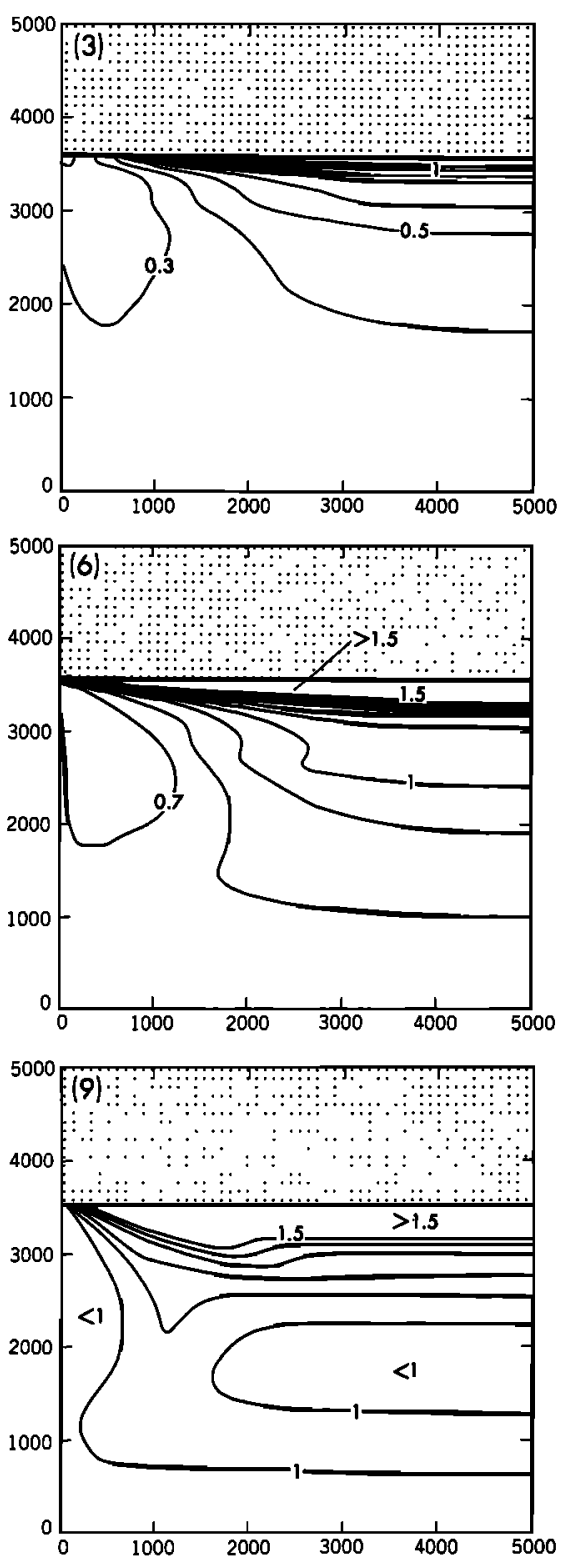

Fig. 12. The ratio of CFC age (Figure 11) to the idealized age tracer (Figure 8). See Figure 5 for further explanation.

Weiss et al. assume. Pickart et al. [1989] have recently shown in a study of the deep western boundary current of the North Atlantic, which is similar in context to the Weiss et al. study, that the error resulting from ignoring these terms can be quite substantial.

The question remains whether the difference in sensitivity of the tracers to mixing can provide useful constraints that could be used to estimate the mixing. Our results show that the tritium- ${ }^{3} \mathrm{He}$ pair and the CFCs behave quite similarly in the upper main thermocline and are thus not too encouraging in this respect. Since we cannot offer a direct way of using the tracers to determine the mixing, we suggest, as was stated previously, that in principle the mixing can be derived via (6). From our study we cannot tell how easy this would be to do, nor can we determine whether our estimates of the limits are sufficient to place additional constraints. These questions should be the subject of further investigations. It would also be interesting to test the concept of ventilation age as stated by (6) in a three-dimensional general circulation model with a steady circulation field in order to study the effect of upwelling and mixing with deeper water.

This study also illustrates the importance of a direct advective input from the outcrop region of the gyre in order to reproduce the basic features of the tracer distributions. Lateral mixing across streamlines is apparently a very inefficient ventilation process with a circulation pattern such as that we have used. This conclusion supports the implication of the tritium box model study of Sarmiento [1983] that the Sverdrup transport within the subtropical gyre may receive tritium injections directly, presumably by convection when it passes through the outcrop region in the northern part of the gyre. However, the circulation pattern we have used is different from that of the real ocean, so that our results can only be considered suggestive. The issue of how tracers 
enter into the gyre is a very important one that needs to be further addressed.

Acknowledgments. Nancy Duprey and Phil Tunison assisted greatly in preparation of the manuscript. Support from National Science Foundation grant OCE 8613326, along with National Oceanic and Atmospheric Administration grant NA84-EA-D00057, is gratefully acknowledged. G.P.T. was supported by a postdoctoral stipend from the German Research Society.

\section{REFERENCES}

Broecker, W. S., T. H. Peng, and M. Stuiver, An estimate of the upwelling rate in the equatorial Atlantic based on the distribution of bomb radiocarbon, J. Geophys. Res., 83, 6179-6186, 1978.

Chemical Manufacturers Association, Production, Sales and Calculated Release of CFC 11 and 12 Through 1984, Report of the Fluorocarbon Panel, edited by E. F. Gormley, Washington, D. C., 1985.

Cunnold, D. M., R. G. Prinn, R. A. Rasmusen, P. G. Simmonds, F. N. Alyea, C. A. Cardelino, A. J. Crawford, P. J. Fraser, and R. D. Rosen, Atmospheric lifetime and annual release estimates for $\mathrm{CFCl}_{3}$ and $\mathrm{CF}_{2} \mathrm{Cl}_{2}$ from 5 years of ALE data, J. Geophys. Res., $91,10,797-10,817,1986$

Dreisigacker, E., and W. Roether, Tritium and ${ }_{90} \mathrm{Sr}$ in North Atlantic surface water, Earth Planet. Sci. Lett., 38, 301-312, 1978.

Fuchs, G., Ventilation der Warmwassersphare des Nordestatlantiks abgeleitet aus ${ }^{3}$ Helium- und Tritium-Verteilungen, Ph.D. dissertation, 207 pp., Univ. of Heidelberg, Heidelberg, Federal Republic of Germany, 1987.

Jenkins, W. J., Tritium-helium dating in the Sargasso Sea: A measurement of oxygen utilization rates, Nature, 196, 291-292, 1977.

Jenkins, W. J., Tritium and ${ }^{3} \mathrm{He}$ in the Sargasso Sea, J. Mar. Res., $38,533-569,1980$.

Jenkins, W. J., Oxygen utilization rates in the North Atlantic Subtropical Gyre and primary production in oligotrophic systems, Nature, 300, 246-248, 1982.

Jenkins, W. J., ${ }^{3} \mathrm{H}$ and ${ }^{3} \mathrm{He}$ in the Beta Triangle: Observations of gyre ventilation and oxygen utilization rates, J. Phys. Oceanogr., $17,763-783,1987$.

Jenkins, W. J., and W. B. Clarke, The distribution of ${ }^{3} \mathrm{He}$ in the western Atlantic Ocean, Deep Sea Res., 23, 481-494, 1976.

Luyten, J. R., J. Pedlosky, and H. Stommel, The ventilated thermocline, J. Phys. Oceanogr., 13, 292-309, 1983.

Musgrave, D. L., A numerical study of the roles of subgyre-scale mixing and the western boundary current on homogenization of a passive tracer, J. Geophys. Res., 90, 7037-7044, 1985.

Musgrave, D. L., Numerical studies of tritium and ${ }^{3} \mathrm{He}$ in the thermocline, J. Phys. Oceanogr., 20, 344-373, 1990.

Pickart, R. S., N. G. Hogg, and W. M. Smethie, Determining the strength of the deep western boundary current using the chlorofluoromethane ratio, J. Phys. Oceanogr., 19, 940-951, 1989.

Roether, W., On oceanic boundary conditions for tritium, on tritiugenic ${ }^{3} \mathrm{He}$, and on the tritium- ${ }^{3} \mathrm{He}$ age concept, in Oceanic Circulation Models: Combining Data and Dynamics, edited by D. L. T. Anderson and J. Willebrand, pp. 377-407, Kluwer, Hingham, Mass., 1989.

Quay, P. D., M. Stuiver, and W. S. Broecker, Upwelling rates for the equatorial Pacific Ocean derived from the bomb ${ }^{14} \mathrm{C}$ distribution, J. Mar. Res., 41, 769-792, 1983.

Rooth, C. G. H., and H. G. Ostlund, Penetration of tritium into the Atlantic thermocline, Deep Sea Res., 19, 481-492, 1972.

Sarmiento, J. L., A tritium box model of the North Atlantic thermocline, J. Phys. Oceanogr., 13, 1269-1274, 1983.

Sarmiento, J. L., C. G. H. Rooth, and W. Roether, The North Atlantic tritium distribution in 1972, J. Geophys. Res., 87, 80478056, 1982.

Sarmiento, J. L., G. Thiele, R. M. Key, and W. S. Moore, Oxygen and nitrate new production and remineralization in the North Atlantic subtropical gyre, J. Geophys. Res., in press, 1990.

Siegenthaler, U., Modeling the dynamics of the global carbon cycle and other natural systems, Habilitation thesis, Phys. Inst., Univ. of Bern, Bern, Switzerland, 1982.

Stommel, H., The westward intensification of wind-driven ocean currents, Eos Trans. AGU, 29, 202-206, 1948.

Thiele, G., W. Roether, P. Schlosser, R. Kuntz, G. Siedler, and L. Stramma, Baroclinic flow and transient-tracer fields in the Canary-Cape Verde Basin, J. Phys. Oceanogr., 16, 814-826, 1986.

Warner, M. J., and R. F. Weiss, Solubilities of chlorofluorocarbons 11 and 12 in water and seawater, Deep Sea Res., 32, 1485-1497, 1985.

Weiss, W., and W. Roether, The rates of tritium input to the world oceans, Earth Planet. Sci. Lett., 49, 435-446, 1980.

Weiss, R. F., J. L. Bullister, R. H. Gammon, and M. J. Warner, Atmospheric chlorofluoromethanes in the deep equatorial Atlantic, Nature, 314, 608-610, 1985.

Wisegarver, D. P., and R. H. Gammon, A new transient tracer: Measured vertical distribution of $\mathrm{CCl}_{2} \mathrm{FCClF}_{2}(\mathrm{~F}-113)$ in the North Pacific Subarctic gyre, Geophys. Res. Lett., 15, 188-191, 1988.

Wunsch, C., An estimate of the upwelling rate in the equatorial Atlantic based on the distribution of bomb radiocarbon and quasi-geostrophic dynamics, J. Geophys. Res., 89, 7971-7978, 1984.

Wunsch, C., Eclectic modelling of the North Atlantic, II, Transient tracers and the ventilation of the eastern basin thermocline, Philos. Trans. R. Soc. London, Ser. A, 325, 201-236, 1988.

J. L. Sarmiento, Atmospheric and Oceanic Sciences Program, Sayre Hall, P.O. Box CN 710, Princeton University, Princeton, NJ 08544 .

G. Thiele, DVFLR, Astronautenbüro, Linder Hohe, D-5000 Köln, Federal Republic of Germany.

(Received October 4, 1988;

revised April 14, 1989;

accepted January 13, 1989.) 